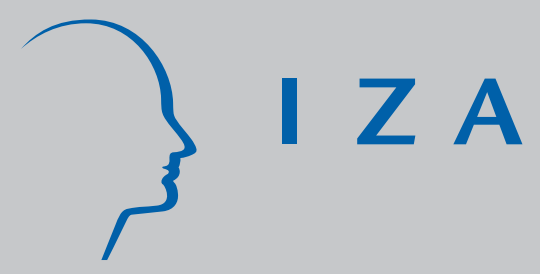

IZA DP No. 3816

Who Becomes an Entrepreneur?

Labor Market Prospects and Occupational Choice

Markus Poschke

November 2008 


\title{
Who Becomes an Entrepreneur? Labor Market Prospects and Occupational Choice
}

\author{
Markus Poschke \\ McGill University \\ and IZA
}

\section{Discussion Paper No. 3816 \\ November 2008}

\author{
IZA \\ P.O. Box 7240 \\ 53072 Bonn \\ Germany \\ Phone: +49-228-3894-0 \\ Fax: +49-228-3894-180 \\ E-mail: iza@iza.org
}

\begin{abstract}
Any opinions expressed here are those of the author(s) and not those of IZA. Research published in this series may include views on policy, but the institute itself takes no institutional policy positions.

The Institute for the Study of Labor (IZA) in Bonn is a local and virtual international research center and a place of communication between science, politics and business. IZA is an independent nonprofit organization supported by Deutsche Post World Net. The center is associated with the University of Bonn and offers a stimulating research environment through its international network, workshops and conferences, data service, project support, research visits and doctoral program. IZA engages in (i) original and internationally competitive research in all fields of labor economics, (ii) development of policy concepts, and (iii) dissemination of research results and concepts to the interested public.
\end{abstract}

IZA Discussion Papers often represent preliminary work and are circulated to encourage discussion. Citation of such a paper should account for its provisional character. A revised version may be available directly from the author. 
IZA Discussion Paper No. 3816

November 2008

\section{ABSTRACT}

\section{Who Becomes an Entrepreneur? Labor Market Prospects and Occupational Choice*}

Why do some people become entrepreneurs (and others don't)? Why are firms so heterogeneous, and many firms so small? To start, the paper briefly documents evidence from the empirical literature that the relationship between entrepreneurship and education is U-shaped, that many entrepreneurs start a firm "out of necessity", that most firms are small, remain so, yet persist in the market, and that returns to entrepreneurship have a much larger cross-sectional variance than returns to wage work. Popular models of firm heterogeneity cannot easily account for the U-shape or for the persistence of low-productivity firms. The paper shows that these facts can be explained in a model of occupational choice between wage work and entrepreneurship where agents are heterogeneous in their ability as workers, and starting entrepreneurs face uncertainty about their project's productivity. Then, if agents' expected productivity as entrepreneurs is increasing and not too concave in their ability as workers, the most and the least able individuals choose to become entrepreneurs. This sorting is due to heterogeneous outside options in the labor market. Because of their low opportunity cost, low-ability agents benefit disproportionately from the ability to pursue only good business projects and abandon low-productivity ones. This also makes them more likely to immediately abandon a project for a new one. Data from the NLSY79 gives support to these two predictions. Individuals with relatively high or low wages when employed, or with a high or low degree, are more likely to be entrepreneurs or to become entrepreneurs, and spend more time in entrepreneurship. Among entrepreneurs, more of the firms run by individuals with low wages when employed, or with a low degree, are abandoned after only a year.

JEL Classification: E20, J23, L11, L16

Keywords: occupational choice, entrepreneurship, firm entry, selection, search

Corresponding author:

Markus Poschke

McGill University

Economics Department

855 Sherbrooke St West

Montreal QC H3A 2T7

Canada

E-mail: markus.poschke@mcgill.ca

\footnotetext{
* I would like to thank Andrea Caggese, Antonio Ciccone, Russell Cooper, Omar Licandro, Francesc Ortega, Morten Ravn, Thijs van Rens, Gregor Smith, Jaume Ventura, and seminar participants at McGill, Concordia, the Federal Reserve Bank of New York, Queen's, Pompeu Fabra, Warwick, City University London, the Third IZA/World Bank Conference on Employment and Development, the Canadian Economics Association 2008 Meeting, and the XXXI Simposio de Análisis Económico for valuable comments and suggestions.
} 


\section{Introduction}

Why do some people become entrepreneurs (and others don`t)? Why do so many firms fail so early? Why are firms so heterogeneous? With these questions in mind, this paper explores the occupational choice between wage work and entrepreneurship when people are heterogeneous in their ability as workers, and startups differ in productivity. A substantial number of people choose to become entrepreneurs. In the U.S., for instance, the ratio of entrepreneurs to entrepreneurs plus wage and salary workers is $12.8 \%$, using CPS data for 2003 cited in Hipple (2004). This rate is even higher in most other industrialized economies (see Blanchflower 2000). Of course, who becomes an entrepreneur may matter a lot for aggregate productivity and welfare.

Before modeling the occupational choice, I assemble and review some relevant facts about entrepreneurship from the empirical literature. First, do the most or the least able become entrepreneurs? A priori, this is not clear, and depends on what type of firm one thinks of. Lazear (2005, p. 650), for instance, puts it this way:

It is tempting to argue that the most talented people become entrepreneurs because they have the skills required to engage in creative activity. Perhaps so, but this flies in the face of some facts. The man who opens up a small dry-cleaning shop with two employees might be termed an entrepreneur, whereas the half-million-dollar-per-year executive whose suit he cleans is someone else's employee. It is unlikely that the shop owner is more able than the typical executive.

The reverse might be true. As necessity is the mother of invention, perhaps entrepreneurs are created when a worker has no alternatives. Rather than coming from the top of the ability distribution, they are what is left over. This argument also flies in the face of some facts. Any ability measure that classifies John D. Rockefeller, Andrew Carnegie, or, more recently, Bill Gates near the bottom of the distribution needs to be questioned.

Indeed, Section 2.1 shows that upon closer inspection, it results from the empirical literature on entrepreneurship that when educational attainment is used as a proxy for ability, there is a U-shaped relationship between entrepreneurship and ability: Self-employment rates are highest for people with relatively high or low levels of education, and lower for people with intermediate levels of education. This of course only comes out when not imposing a linear specification for education. When just regressing the probability of being an entrepreneur on years of schooling, 
results often are not significant - as may well occur if the underlying relationship is actually U-shaped. $^{1}$

The remainder of Section 2 briefly revisits three better-known facts about entrepreneurship. Firstly, a substantial fraction of entrepreneurs (more than 10\% in the U.S.) make their occupational choice not to pursue some golden opportunity, but "out of necessity". Secondly, the bulk of firms are small, remain so, and yet persist in the market. Many are smaller than popular models of firm entry and survival allow them to be, making structural estimation or calibration of those models hard. Finally, returns to entrepreneurship have a much larger cross-sectional variance than returns to wage or salaried work.

In Section 3, I set out a simple and pretty general model that can explain all these facts. It describes a world where people differ in both productive ability (output as workers) and the productivity of firms they start, and choose the most rewarding occupation. Whereas productive ability is known, the productivity of entrepreneurial projects can only be found out by implementing them, i.e. by becoming an entrepreneur. Average productivity of firms started by a person may however be correlated with his/her productive ability.

Because a project's productivity is not known ex ante, an entrepreneur may happen to start a low-productivity venture and then abandon it in the hope of starting a more productive project next time. The optimal continuation policy hence consists in a reservation productivity, similar to that in McCall (1970) labor market search. Less productive projects are abandoned. This reservation productivity is higher for more able agents. In Section 4, I show that if prospective entrepreneurs' expected productivity increases in their ability and this relationship is weakly convex (or, strictly speaking, not too concave), the most able and the least able people start firms, with agents of intermediate ability choosing to become workers. (A very weak restriction on the production function is also needed.) I also show that not only the optimal reservation productivity, but also the success probability it implies is higher for high-ability agents. This implies that low-ability agents reject more projects and search longer before accepting one.

The pattern of selection into entrepreneurship arises for the following reason: The cost of starting a firm is an opportunity cost in terms of foregone wages. This is higher the more discriminating the reservation productivity policy is. Low-ability agents face low wages and therefore have a low opportunity cost of starting a firm. As long as they have some probability of having a reasonably good idea and if entry costs are not too high, searching for that idea

\footnotetext{
${ }^{1}$ Lazear, following his observation, then goes on to focus on heterogeneity in the structure of skills, and not in ability. The potential importance of other dimensions of heterogeneity notwithstanding, the main contribution of the model proposed in this paper is to explain the at first sight puzzling entrepreneurship-ability relationship.
} 
is worthwhile. High-ability agents have particularly high potential benefits. But agents of intermediate ability fall in between, and as a result do not find it optimal to start a firm.

In considering a setting with two dimensions of heterogeneity, the paper goes beyond the classic models of entrepreneurial choice of Lucas (1978) and Kihlstrom and Laffont (1979). With only one dimension of heterogeneity as there, it is relatively obvious who will start a firm: the least risk averse, or the most able entrepreneurs. This however does not square well with the empirical evidence on entrepreneurship and ability, or even with casual observation. Cagetti and De Nardi (2006) do consider a model of occupational choice with two dimensions of ability. However, their entrepreneurial ability is a binary variable, just indicating whether someone is able to start a firm or not. They then focus on how the possibility of starting a firm shapes the wealth distribution and the distribution of returns to entrepreneurship when there are financial constraints - quite distinct from the role of heterogeneity in this paper.

The model is close to another classic, though: the Roy (1951) model of occupational choice. Jovanovic (1994) analyzes such a Roy model with known, heterogeneous managerial and working abilities. The model here extends this by uncertainty about a startup's productivity, and by agents' ability to search for a good project. Section 5 shows how two crucial differences, the fact that one of the occupations considered is entrepreneurship and the introduction of search, substantially shape the predictions of the occupational choice model. As a result, the model proposed here matches all the facts presented in Section 2, in particular the U-shaped relationship between education and ability.

The main predictions of the model are that individuals with relatively high or low ability are more likely to become entrepreneurs, and that among these, low-ability agents are more discriminating in their choice of project. The final section presents empirical evidence on these predictions, using data from the National Longitudinal Survey of Youth (NLSY79). I find that individuals with relatively high or low wages when employed, or with a high or low degree, are more likely to be entrepreneurs or to become entrepreneurs, and spend more time in entrepreneurship. Among entrepreneurs, more of the firms run by individuals with low wages when employed, or with a low degree, are abandoned after only a year. These findings give support to both of the main predictions of the model.

\section{Some facts on entrepreneurship}

This section documents several relevant facts about entrepreneurship, some well-known, some new. Firstly, the relationship between entrepreneurship and education is U-shaped. That is, 
people with very low or high levels of education are more likely to be entrepreneurs than people with intermediate levels of education. Secondly, there is a substantial fraction of people who become entrepreneurs "out of necessity," and not to pursue an opportunity. This fits with the third fact: most firms are small. Most of these firms remain small and are not much more likely to exit than their larger counterparts. Many existing models have trouble accounting for the smallest of them. Finally, returns to entrepreneurship have a much higher variance than returns to being an employee. This emerges robustly from the recent literature on entrepreneurship and will therefore be reiterated only briefly here.

\subsection{Who becomes an entrepreneur? Entrepreneurship and educational at- tainment}

Are more productive or less productive people more likely to become entrepreneurs? As suggested by the quote from Lazear (2005), either argument might be made, depending on the type of firm one is thinking of. This also suggests that the answer does not have to be either/or. This section presents evidence on the relationship between entrepreneurship and ability, with the following result:

Fact 1 The relationship between entrepreneurship and education is U-shaped, i.e. people with low or high levels of education are more likely to be entrepreneurs than people with intermediate levels of education.

Whereas there is an abundant literature on the impact of an additional year of schooling on wages or salaries of employees, the relationship between entrepreneurship and schooling has received much less attention, and much less sophisticated econometric treatment. Therefore, I will simply focus on results in the literature on the proportion of entrepreneurs by educational attainment.

Studies that look only for a linear effect, e.g. by regressing the probability of being an entrepreneur on years of schooling, often remain inconclusive. This is also the case for the meta-study by van der Sluis, van Praag and Vijverberg (2003). The reason for this is that on closer inspection, as shown below, a U-shape appears: People at the extremes of the education distribution are more likely to be entrepreneurs than people with intermediate levels of education. Looking for a purely linear relationship will hide the U-shape and most likely yield insignificant estimates.

Table 1 summarizes recent evidence. It shows self-employment rates by educational category from a variety of sources, covering different countries and time periods. The columns refer to 
elementary school $(\mathrm{E})$, less than high school $(<\mathrm{HS})$, high school $(\mathrm{HS})$, less than college $(<\mathrm{C})$, college $(\mathrm{C})$, and advanced degrees $(>\mathrm{C})$. Not all sources report data for all of the educational categories. More detail on the sources can be found in Table 2 .

Table 1: Entrepreneurship rates by education category

\begin{tabular}{llcccccc}
\hline \hline & & \multicolumn{7}{c}{ educational attainment } \\
& data source & $\mathrm{E}$ & $<$ HS & HS & $<\mathrm{C}$ & $\mathrm{C}$ & $>\mathrm{C}$ \\
\hline Borjas and Bronars (1989) & U.S., 1980 Census & & 4.8 & 4.2 & 4.6 & 6.5 & \\
Hamilton (2000) & U.S., 1984 SIPP & & 12.6 & 11.1 & 12.6 & 15 & \\
Hipple (2004) (unincorporated) & U.S., 2003 CPS & & 9.1 & 8.7 & 8.2 & 7.5 & 9.1 \\
Hipple (2004) (incorporated) & U.S., 2003 CPS & & 2.1 & 3.1 & 3.9 & 5.5 & 6.6 \\
Lin, Picot and Compton (2000) & Canada, 1994 & 18.4 & 13.5 & 11.4 & 10.1 & 11.1 & 13.2 \\
Schjerning and Le Maire (2007) & Denmark, 1980-96 & 10.9 & & 10.9 & 7.4 & 3.6 & 12.9 \\
\hline \hline
\end{tabular}

Notes: Sources: Author's computations from Borjas and Bronars (1989), Table 2, Hamilton (2000), Table 1, Hipple (2004), Table 3, Lin et al. (2000), Table 3, Schjerning and Le Maire (2007), Table A.1. Borjas and Bronars (1989): Results are similar for black and Asian men. Some papers refer to self-employment rates, not entrepreneurship rates. Yet, as these self-employed can have employees, the term used here seems more apt.

Table 2: Entrepreneurship rates and education: details on data sources

\begin{tabular}{ll}
\hline \hline Blanchflower (2000) & $\begin{array}{l}\text { micro data from } 19 \text { countries, from Eurobarometer Surveys and } \\
\text { General Social Survey, 1975-1996, ages 16-64. }\end{array}$ \\
Borjas and Bronars (1989) & $\begin{array}{l}\text { U.S., 1980 Census: white men aged 25-64, residing in metropo- } \\
\text { litan areas, not employed in agriculture. }\end{array}$ \\
Hamilton (2000) & $\begin{array}{l}\text { U.S., 1984 SIPP: male school leavers aged 18-65 working in the } \\
\text { nonfarm sector. }\end{array}$ \\
Hipple (2004) & U.S., 2003 CPS: men and women, aged 16 and older. \\
Lin et al. (2000) & Statistics Canada 1994 Survey of Labour and Income Dynamics \\
Schjerning and Le Maire & (SLID), ages 15-64. \\
Statistics Denmark Integrated Database for Labor Market Re- & search (IDA) and Danish Income Registry (IKR), 1980-1996, \\
& ages 30-55. \\
\hline \hline
\end{tabular}

The most remarkable feature of the data reported in Table 1 is that self-employment rates are higher for the lowest and highest levels of schooling, and lower for intermediate levels. Hence, the relationship between the self-employment rate and educational attainment is U-shaped. This holds across data sources, time periods, and (some) countries, giving the regularity some support. 
It also holds in the NLSY data used in this paper, as shown in Section 6. The only group for which it does not hold is the subgroup of the incorporated self-employed. This exception arises because small businesses are unlikely to incorporate. Using recent data from the new Panel Study of Entrepreneurial Dynamics (PSED), Campbell and De Nardi (2007) also find a U-shape of the probability of being in the process of starting a business with respect to schooling (see their Figure 2).

Econometric exercises show that these differences are not simply due to e.g. cohort effects. The U-shape in education persists when regressing the probability of being an entrepreneur on a set of demographics using discrete choice models. This is found both by Blanchflower (2000) in data across 19 OECD countries, and by Schjerning and Le Maire (2007) in Danish data, using very fine education categories. Blanchflower finds that controlling for age, education, gender, household size, the number of children under the age of 15 in the household and the genderspecific country unemployment rate, "the least educated (age left school < age 15) and the most educated (age left school > 22 years) have the highest probabilities of being self-employed" (p. 488). This pattern is statistically significant. Schjerning and Le Maire, controlling for age, wealth, number of children by age, marital status, immigrant status and origin, and the spouse's self-employment status still find that the probability of being self-employed is lowest for the intermediate education categories of post secondary education and a short cycle of higher education, and higher at the extremes. A linear specification for education would not be able to pick this up. Evans and Leighton (1989) for instance, using years of schooling as a measure of education, do not find it to be significant when controlling for urban vs rural, experience, unemployment status, father's occupation, and some sectors. As far as the evidence goes, the U-shaped relationship between entrepreneurship and educational attainment hence emerges as a pretty robust fact.

\subsection{Why start a firm? Opportunity vs necessity}

Are all entrepreneurs out to pursue some golden opportunity? Despite the fact that many large firms started small, most firms stay small, and yet they persist. In fact,

Fact 2 There is a substantial fraction of people who become entrepreneurs "out of necessity", and not to pursue an opportunity.

This results from data collected through the Global Entrepreneurship Monitor (GEM) project in 47 industrialized and developing countries. The GEM is an academic research consortium led 
by London Business School and Babson College. Its data provide the broadest information on entrepreneurship across countries.

Table 3: Fraction of entrepreneurs starting a firm "out of necessity" (GEM data)

\begin{tabular}{lrllll}
\hline \hline Western Europe & & other OECD & \multicolumn{3}{c}{ Latin America } \\
Belgium & $10.8 \%$ & Australia & $16.7 \%$ & Argentina & $39.1 \%$ \\
Denmark & $6.1 \%$ & Canada & $16.9 \%$ & Brazil & $46.7 \%$ \\
Spain & $16.4 \%$ & Japan & $26.3 \%$ & average & $42.9 \%$ \\
Finland & $9.7 \%$ & New Zealand & $13.5 \%$ & & \\
France & $23.0 \%$ & USA & $12.3 \%$ & Asia & \\
Germany & $26.5 \%$ & average & $17.1 \%$ & Singapore & $15.7 \%$ \\
Iceland & $7.1 \%$ & & & & \\
Ireland & $16.4 \%$ & Transition Economies & & Africa & \\
Italy & $13.5 \%$ & Croatia & $37.3 \%$ & South Africa & $39.2 \%$ \\
Netherlands & $10.2 \%$ & Hungary & $33.0 \%$ & & \\
Norway & $8.0 \%$ & Slovenia & $19.3 \%$ & & \\
Sweden & $12.6 \%$ & average & $29.9 \%$ & & \\
UK & $13.7 \%$ & & & & \\
average & $13.4 \%$ & & & & \\
\hline \hline
\end{tabular}

Notes: Tabulated data are from the macro overview data of the GEM (micro data is also available). It has been downloaded from http://www.entrepreneurship-sme.eu/.

The GEM survey targets people aged 18 to 64 years who are involved in some nascent entrepreneurial activity. The relevant group is identified in the context of household surveys. Table 3 shows the fraction of people responding to "Are you involved in this start-up to take advantage of a business opportunity or because you have no better choices for work?" as "have no better choice." In the GEM data, this is called the Necessity Entrepreneurial Activity Index. The numbers shown are time averages for the period 2001 to 2005 for the countries where observations for at least 4 years were available.

Two facts stand out. First, the fraction of entrepreneurs "out of necessity" is by far the highest in Latin America, South Africa, and Eastern European transition economies. Most likely, issues of (in)formality play a role here. Secondly, there is a substantial fraction of entrepreneurs "out of necessity" everywhere, even in industrialized countries. In most countries, the number is above $10 \%$. The average for industrialized countries is $14.4 \%$. Hence, not all entrepreneurs are out to innovate or pursue a golden opportunity. 


\subsection{Most firms are (very) small}

Given the presence of low-ability entrepreneurs, combined with a substantial fraction of entrepreneurs starting firms "out of necessity", the next fact is not surprising.

Fact 3 Most firms are small. Most of these firms remain small and, conditional on age, are not much more likely to exit than their larger counterparts.

For instance, in the U.S., $55 \%$ of employer firms have less than 5 employees. In addition, there are around 10 million self-employed. While small firms are more likely to exit, the difference is small once age is controlled for (Bartelsman, Scarpetta and Schivardi 2003, Figure 6). Hence, small firms are there to stay. They are not necessarily future large firms (although of course large firms tend to start small), nor are they doomed to disappear quickly. They are not simply due to systematic size differences across industries either, as e.g. Foster, Haltiwanger and Krizan (2001) document that within-industry productivity dispersion dominates that between industries.

Recent research attempting to match the firm size distribution has mainly focussed on its right tail (see e.g. Luttmer 2007, Chatterjee and Rossi-Hansberg 2008), not paying much attention to the left tail. Indeed, popular models have problems accounting for just how small and persistent small firms can be. For instance, in settings like that of Hopenhayn (1992) and the many models based on it, a fixed cost or a uniform outside option imply that there is a strictly positive minimum firm size. In the data, however, this minimum size is zero when measured in terms of employees. Hence, estimated versions of such models have trouble accounting for small firms and their persistence. Due to the non-linearity of these models, this may affect other parameter estimates and predictions. Heterogeneity in outside options could solve that problem, as shown below in the model.

\subsection{Returns to entrepreneurship}

Fact 4 Returns to entrepreneurship have a much higher cross-sectional variance than wages.

This emerges very robustly from the recent literature on entrepreneurship (see e.g. Hamilton 2000, Moskowitz and Vissing-Jørgensen 2002). Whereas measurement issues pose serious problems in comparing the average return to entrepreneurship to that to wage work or to public equity (Hamilton 2000, Moskowitz and Vissing-Jørgensen 2002, Cagetti and De Nardi 2006), the difference in variance is so large, and largely immune to shifts in the mean, that there is no disagreement on it. 
To illustrate, in an early study, Borjas and Bronars (1989) found that the standard deviation of log weekly income for the self-employed is up to twice that of wage-earners. Depending on the measure used for income from self-employment, it is between two and almost four in the sample from the SIPP used by Hamilton (2000).

These four facts are related. They suggests that: entrepreneurs have very heterogeneous outside options, so some become entrepreneurs "out of necessity". These may (a conjecture) be mainly people with low levels of education. The firms they run most likely will remain small, if they manage to survive. Suppose that some variance in returns to entrepreneurship also arises from heterogeneous quality of projects. Finally suppose that, while any budding entrepreneur could end up running projects of varying return, those with higher education would on average run their projects better, or run better projects. Then it is clear that the fact that entrepreneurs come from the extremes of the ability distribution implies that the observed post-selection crosssectional variance in returns will be high relative to the variance in returns any individual might face. Hence, selection from the extremes of the ability distribution, arising from heterogeneous outside options, increases observed variance in returns to entrepreneurship.

The model developed in the next section shows how selection from the extremes can occur naturally in a pretty general setting. It also matches the other facts. Moreover, it suggests that one-sided selection models, as usually employed in empirical work, will only capture part of the selection mechanism.

\section{The economy}

Time is discrete. The economy consists of a continuum of risk-neutral individuals of measure 1. People derive utility from consumption, and can earn income either as workers or by running their own firm. Every period, they retire with probability $\lambda>0$, and a measure $\lambda$ of people newly enter the labor market. When an entrepreneur retires, the firm is dissolved. Employees can however immediately find a new job on a competitive labor market. Future utility is discounted at a rate $r>0$. Combined with the retirement probability, this implies discounting future utility using a discount factor $\beta=(1-\lambda) /(1+r) \in(0,1)$.

Firms produce a homogeneous good, which is used as the numéraire. They produce output with the production function

$$
y(\alpha, n)=\alpha n^{\gamma}, \quad 0<\gamma<1 .
$$

This production function combines as inputs one manager/owner, who is essential to operate 
the firm, with a labor input of $n$ efficiency units. (Any individual can run at most one firm at any moment in time.) Production exhibits decreasing returns to scale in the only variable input, labor, so that optimal firm size is finite. ${ }^{2}$ This could be due for instance to limits in managers' span of control (Lucas 1978): as activity expands, it becomes more difficult to control, and the marginal product of the variable factor diminishes. Firms vary in their total factor productivity $\alpha$, which is constant over time for a given firm.

While firms differ in their productivity, individuals differ in their productive ability $a$. In the following, this will be referred to as "ability" for short, to distinguish it from productivity, which is a firm-level concept. Ability $a$ is observable. Workers are perfectly substitutable in production; a worker with ability $a$ can provide $a$ efficiency units of labor input. Assume that $a$ is weakly positive and that its distribution in the population can be described by some continuous $p d f$ with finite, strictly positive mean and variance.

Individuals have the choice between working or running a firm for a living. A would-be entrepreneur can start a firm by putting into practice some business idea. For the moment, suppose that there is no entry cost. It is well-documented that it is hard to precisely assess the quality of a project and of its implementation ex ante, before starting the firm. ${ }^{3}$ Hence, assume that prior to entry, a potential entrepreneur faces a known probability distribution of potential values of productivity $\alpha$ his/her project could have. The precise productivity of a concrete project, however, is only revealed upon starting a firm.

Timing is as follows. At the beginning of any period, agents face the choice between working and starting a firm. Ability $a$ being observable, agents know their return to working. People who already run a firm also know the quality of that project and can take this into account in their choice. The productivity of a new firm, however, is not known. Only the distribution of productivities is known, so agents make their decision based on this. If they start a firm, they learn their project's productivity $\alpha$. They can then either pursue that project and start production the following period, or abandon the project. As a result, there is an entry cost in terms of foregone wages: It takes a period to start production, so starting a firm entails an opportunity cost equal to foregoing a period's wages.

A firm's productivity depends on the quality of its founder's idea and management. Suppose that more able (higher $a$ ) individuals have a tendency to have better ideas, or that there are

\footnotetext{
${ }^{2}$ The setting is easy to extend to include a variable capital input. The necessity of the fixed managerial input then still ensures decreasing returns to variable inputs, guaranteeing finite optimal firm size.

${ }^{3}$ Theoretically, this point has been made many times, see for instance Jovanovic (1982). The clearest supporting evidence comes from high failure rates of young firms. This is amply documented, for some recent estimates of survival hazards see e.g. Bartelsman et al. (2003).
} 
some general skills which are useful both in production and for running a firm. To capture this, assume that at startup, entrepreneurs with ability a draw their firm's productivity $\alpha$ from some distribution with $c d f \Phi^{a}(\cdot)$, where $a$ enters as a parameter. All these distributions are identical up to a translation of location that is given by a monotonic, twice differentiable function $g(a)$. It is useful to define $H(\cdot)=\Phi^{a_{0}}(\cdot)$, where $a_{0}$ is the $a$ such that $g\left(a_{0}\right)=0$. Then $\Phi^{a}(\alpha)=\Phi^{a^{\prime}}\left\{\alpha-\left[g(a)-g\left(a^{\prime}\right)\right]\right\}$ for any $a$ and $a^{\prime}$. If $g^{\prime}(a)>0$, higher-ability entrepreneurs draw from better distributions in a first order stochastic dominance sense. Higher moments are not affected by $a$. Also assume that $H$ is continuously differentiable and has full support in $\mathbb{R}$.

To summarize, the population consists of individuals of heterogeneous ability $a$. To make a living, each of them has the choice between working or running a firm. In case they start a firm, the firm's productivity $\alpha$ is not known ex ante, but the distribution is known, and improves with an individual's ability $a$.

A competitive equilibrium in this economy consists of a wage schedule $w(a)$ and a distribution of agents over activities such that taking prices and wages as given, agents choose their occupation optimally, firms choose employment to maximize profits, and the labor market clears. The firm productivity distribution is directly determined by the distribution of agents over activities and their optimal occupational choice.

\section{Occupational choice}

The occupational choice problem has the following basic structure. Workers find it optimal to start a firm if this yields higher value than employment. The latter depends on the worker's productive ability. This is also true for the former, because more able workers tend to run more productive firms. As a result, not everyone will find it optimal to start a firm; who does so depends on the relationship between $\alpha$ and $a$. Once a firm has been started, the owner will only pursue the concern if this gives a higher value than either giving it up and looking for a job, or giving it up and trying out a new project. The former is never going to be optimal: any startup has the same expected value, so anyone who finds it optimal to start a firm once (rather than work) is going to find it optimal again, even if the first project turned out to be unsuccessful. The other option of starting a new project, however, implies that entrants will only continue if they are sufficiently productive. For someone who realizes that his business idea was not good, it is preferable to try out a new idea instead.

A starting entrepreneur's problem is thus analogous to a McCall (1970) search problem in the labor market. Someone who has decided that trying to start a firm is the optimal thing 
to do also has to decide which level of productivity is good enough to continue operating. The reason is that the entrepreneur can always decide to try a new project next period, at the cost of abandoning the current one. Let the value of running a firm with productivity $\alpha$ forever be $F(\alpha)$. Let expected firm value be $V(a)$. An entrepreneur who has just realized that his project has productivity $\alpha$ then has two options: pursue it and get $F(\alpha)$ next period, or try another project and get $V(a)$ next period. He is thus indifferent between the two actions if $F(\alpha)=V(a)$. This defines a reservation productivity $\alpha_{R}$ : for draws of $\alpha$ above $\alpha_{R}$ it is optimal to continue, and for draws below $\alpha_{R}$ it is optimal to try a different project. Firm value at the reservation productivity satisfies

$$
F\left(\alpha_{R}(a)\right)=\beta \mathbb{E}\left\{\max \left[F(\alpha), F\left(\alpha_{R}(a)\right)\right] \mid a\right\}=V(a)
$$

The expectation is conditional on $a$ because the entrepreneur's ability determines the distribution from which $\alpha$ is drawn. Because different entrepreneurs face different distributions, the reservation productivity $\alpha_{R}(a)$ is a function of $a$. By standard arguments, this functional equation in $\alpha_{R}(a)$ has a unique solution.

Agents' occupational choice problem then consists of comparing the value of starting a firm, $V(a)$, to the value of working. Denote the latter by $W(a)$. As $a$ does not change over an individual's life, agents make the same choice every period, or we can think of them as making an occupational choice when entering the labor market. With perfectly substitutable labor inputs and a competitive labor market, the wage $w(a)$ is linear in $a$, and so is the value $W(a)$ of working forever. The shape of $V(a)$ then determines the pattern of occupational choice. For this, the relationship between $a$ and $\Phi$ given by $g(a)$ is crucial.

To derive the shape of $V(a)$, first rewrite the expression for the reservation productivity in a way common in the search literature as

$$
F\left(\alpha_{R}(a)\right)=\frac{\beta}{1-\beta} \int_{\alpha_{R}(a)}^{\infty} F\left(\alpha^{\prime}\right)-F\left(\alpha_{R}(a)\right) \mathrm{d} \Phi^{a}\left(\alpha^{\prime}\right) .
$$

For a detailed derivation, see the appendix. This equation characterizes the reservation productivity as the level of $\alpha$ at which the marginal cost and benefit of searching another period, or trying again, are just equal. Trying again entails foregoing the value in hand, given on the left hand side (LHS) of equation (3). In return, it may result in drawing a productivity $\alpha^{\prime}$ higher than the one in hand. This gain is given by the expression on the right hand side (RHS). Figure 1 plots the two sides of equation (3) against the current draw of productivity, $\alpha$, for the case of linear $F$. The cost of searching again increases in the current draw $\alpha$ and is given by 
the upward-sloping line. The benefit falls in $\alpha$, as shown for instance in Ljungqvist and Sargent (2004). The reason is that the higher the current draw, the lower the probability of a subsequent, better draw, and the lower the marginal gain from such a better draw. The downward-sloping lines trace out the benefit for three different levels of $a$ for the case of $g^{\prime}(a)>0$.

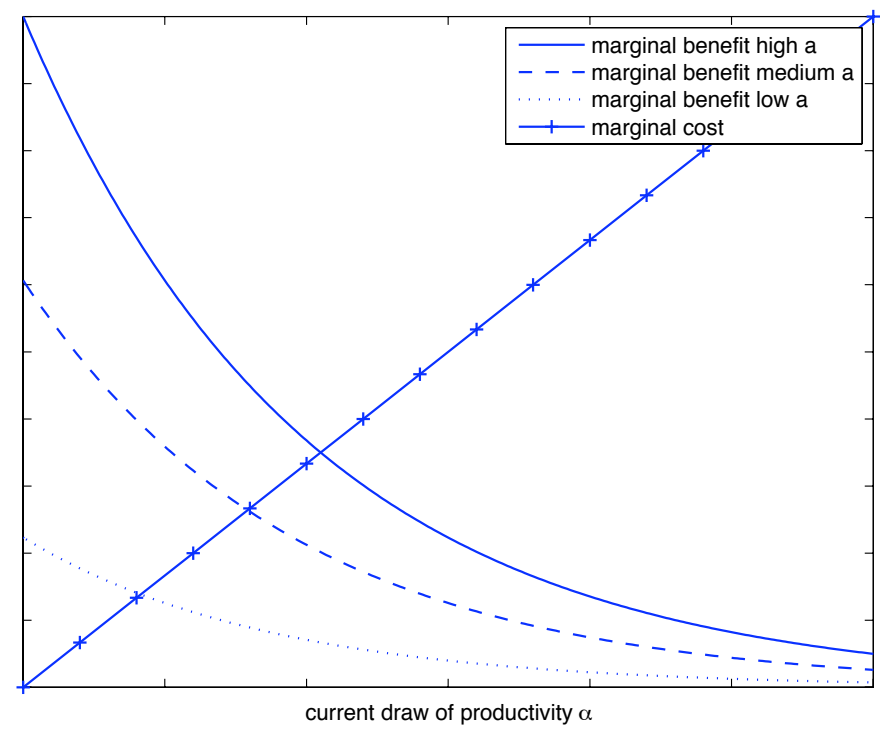

Figure 1: Determination of the reservation productivity: marginal cost and marginal benefit of drawing again

How do the reservation productivity and entry value vary with $a$ ? This clearly depends on $g(a)$. Note first that if all agents, no matter their ability, face the same productivity distribution $\left(g^{\prime}(a)=0\right)$, the marginal benefit of drawing again is independent of $a$. As a consequence, the reservation productivity $\alpha_{R}$ is also independent of $a$, as is the value of trying. This value must be strictly positive for the labor market to clear. Otherwise (if $V \leq 0$ ), all agents would desire to become workers, but there would not be any firms demanding labor. With $V>0$ and $W(a)$ increasing monotonically from zero to infinity, there is a unique intersection $a_{L}$ at which $V=W\left(a_{L}\right)$. Agents with $a \leq a_{L}$ start firms, while agents with $a>a_{L}$ become workers. If everyone faces the same opportunities as an entrepreneur but opportunities in employment differ, the least able workers choose entrepreneurship.

The more interesting and intuitively appealing case is that in which $g^{\prime}(a)>0$, and more able workers also make better entrepreneurs, on average. To obtain the shape of $V$ for that case, 
first rewrite the marginal benefit of trying again, using the properties of $\Phi^{a}$ :

$$
\frac{\beta}{1-\beta} \int_{\alpha}^{\infty} F\left(\alpha^{\prime}\right)-F(\alpha) \mathrm{d} \Phi^{a}\left(\alpha^{\prime}\right)=\frac{\beta}{1-\beta} \int_{\alpha-g(a)}^{\infty} F\left(\alpha^{\prime}+g(a)\right)-F(\alpha) \mathrm{d} H\left(\alpha^{\prime}\right) \equiv M B(\alpha, a),
$$

where $\alpha$ is the productivity draw currently in hand, and $\alpha^{\prime}$ is next period's draw. Written this way, ability $a$ affects the payoff and the cutoff instead of the distribution. Clearly, by the properties of the production function, $g$ and $H, M B$ is continuously differentiable. By equation (3), this carries over to $F\left(\alpha_{R}(a)\right)$ and to $V(a)$. Taking the first derivative of $M B$ with respect to $a$ yields

$$
\frac{\partial M B}{\partial a}=\frac{\beta}{1-\beta} \int_{\alpha-g(a)}^{\infty} F^{\prime}\left(\alpha^{\prime}+g(a)\right) g^{\prime}(a) \mathrm{d} H\left(\alpha^{\prime}\right)
$$

As firm value increases in productivity $\left(F^{\prime}>0\right)$, this expression has the same sign as $g^{\prime}(a)$. Hence, in Figure 1, an increase in $a$ shifts the marginal benefit line up if $g^{\prime}>0$. As a result, both the reservation productivity $\alpha_{R}(a)$ and the value of trying $V(a)$ increase in $a$. (If $g^{\prime}<0$, both fall in $a$, resulting again in the least able workers becoming entrepreneurs, as in the case with $g^{\prime}=0$.)

The second derivative of $M B$ with respect to $a$ is

$$
\begin{gathered}
\frac{\partial^{2} M B}{\partial a^{2}}=\frac{\beta}{1-\beta}\left\{\int_{\alpha-g(a)}^{\infty} F^{\prime}\left(\alpha^{\prime}+g(a)\right) g^{\prime \prime}(a)+F^{\prime \prime}\left(\alpha^{\prime}+g(a)\right) g^{\prime}(a)^{2} \mathrm{~d} H\left(\alpha^{\prime}\right)\right. \\
\left.+F^{\prime}(\alpha) g^{\prime}(a)^{2} h(\alpha-g(a))\right\}
\end{gathered}
$$

where $h(\cdot)=H^{\prime}(\cdot)$, the $p d f$ associated to $H$. The first two terms in (6) give the effect of the shapes of $F$ and $g$ on $M B$, whereas the last one results from the higher probability of exceeding any given threshold that comes with a higher $a$. From the assumptions on technology, $F^{\prime \prime}>0$. Thus, if $g$ is weakly convex $\left(g^{\prime \prime} \geq 0\right)$, the marginal benefit of trying again is convex in $a$ for any fixed threshold $\alpha$. Note that this also goes through if $F$ is linear. The driving factor is that drawing from a better distribution not only raises expected productivity, but also raises the probability of exceeding any given threshold. Where a reservation productivity rule is optimal, this is a source of further gain.

As $M B$ is convex in $a$ for any given threshold $\alpha$, this is also the case for $F\left(\alpha_{R}(a)\right)$ and thus for $V(a)$. The implications for the reservation productivity depend on the shape of $F$. Note again that the result does not rely on convexity of $F$ or $g$, it is purely due to the opportunity to 
search, and to reject low draws. (Evidently, convexity of $F$ or $g$ would make $V$ more convex.) ${ }^{4}$

To obtain the final results on occupational choice, some last results on the limits of $V$ are required. First of all, $V(0)>0$ as long as $\Phi^{0}(0)<1$, i.e. there is some probability of drawing an $\alpha>0$ even if $a=0$. This is ensured trivially by the assumption that $H$, and thereby all $\Phi^{a}$, has full support in $\mathbb{R}$. Hence, $V(0)>W(0)$ because of the ability to search. Agents with very low ability become entrepreneurs. However, for the labor market to clear, not all agents can become entrepreneurs. Together with continuity of $V$ and $W$, this implies that there is a threshold $a_{L}$ such that agents with $a \leq a_{L}$ become entrepreneurs.

At the upper end of the ability distribution, agents become entrepreneurs because $V$ is convex, unless $V$ asymptotically becomes linear with slope lower than that of $W$. This does not occur if either $F$ is convex (as it is under very general assumptions on technology, e.g. $\gamma>0$ in the present context) or $g$ is convex. By continuity, this implies that there is a threshold $a_{H}$ such that agents with $a \geq a_{H}$ become entrepreneurs. While it could be argued that the result at the top of the ability distribution is driven mainly by convexity of the return function due to variable inputs (together with $g^{\prime}>0$ ), the result at the bottom of the ability distribution is clearly due to search. ${ }^{5}$ Figure 2 plots $V$ and $W$ against $a$. The following proposition summarizes the results.

\section{Proposition 1 Occupational choice:}

a) If $g^{\prime}(a)=0$, the value of starting a firm is independent of ability. Then there is a threshold $a_{L}$ such that agents with $a \leq a_{L}$ start firms and agents with $a>a_{L}$ become workers.

b) If $g^{\prime}(a)<0$, the reservation productivity $\alpha_{R}(a)$ and the value of starting a firm fall in a. Then there is a threshold $a_{L}$ such that agents with $a \leq a_{L}$ start firms and agents with $a>a_{L}$ become workers.

c) If $g^{\prime}(a)>0$, the reservation productivity $\alpha_{R}(a)$ and the value of starting a firm, $V(a)$, increase in a. If $F^{\prime \prime}(\alpha) \geq 0(\gamma \in[0,1))$ and $g^{\prime \prime} \geq 0, V(a)$ is convex in a. ${ }^{4}$ Then there are thresholds $a_{L}$ and $a_{H}\left(a_{L}<a_{H}\right)$ such that agents with $a \leq a_{L}$ or $a \geq a_{H}$ start firms and agents with $a_{L}<a<a_{H}$ become workers.

\footnotetext{
${ }^{4}$ Also, by continuity, $V$ still is convex with $F$ linear and $g$ slightly concave; so $g$ linear is a stricter bound than actually required.

${ }^{5}$ Convexity of the return function and ex ante unknown productivity alone also yield $\mathbb{E} F(\alpha)>F(\mathbb{E} \alpha)$ by Jensen's inequality. If for instance $g(0)=0$, this would also deliver entrepreneurship by low-ability agents. The result in the text is stronger and more general than this. See also the discussion in Section 5.
} 


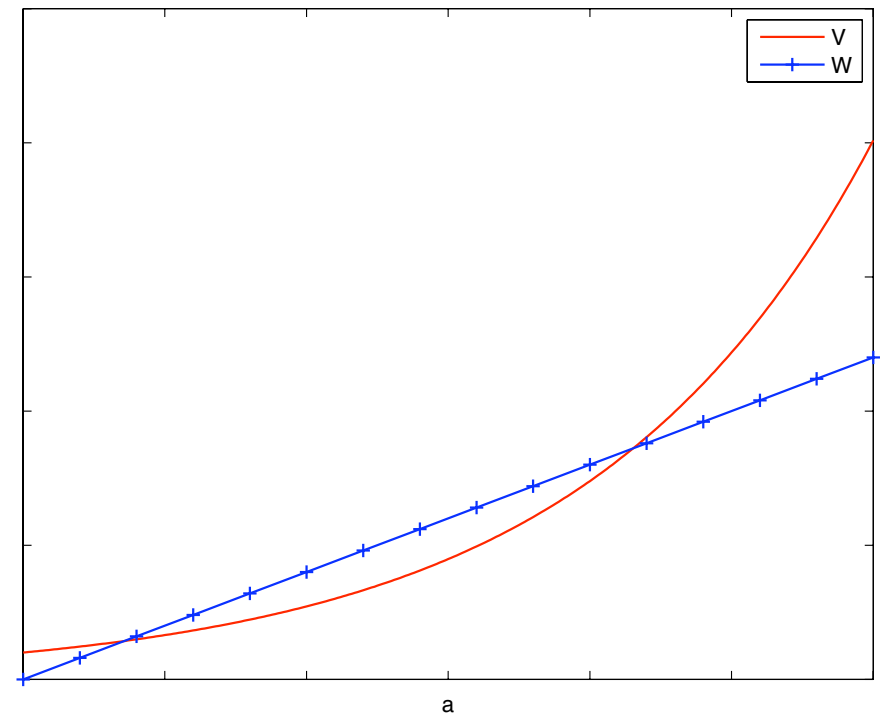

Figure 2: The value of starting a firm $(V(a)$, convex line) and of working $(W(a)$, straight line)

In the latter, most interesting case, entrepreneurship by low-ability agents is due to the ability to search for a good project, and to abandon bad ones. Entrepreneurship by high-ability agents is due to entrepreneurs' ability to leverage their productivity by adjusting variable inputs, resulting in firm value that increases more than linearly in productivity. Said differently, given sufficient variation in the returns of potential projects, people with very low value of participating in the labor market can always do better by searching for a good project - where "good" is relative to their own alternatives, not to other firms. Search puts a floor under how low the value of running a firm can be. As a result, if their own outside option is sufficiently low, it is optimal for these agents to continue running firms at the bottom of the economy-wide productivity distribution. Search matters less at the high end of the ability distribution. More important is the ability to determine the scale of the business as a function of productivity. This possibility distinguishes entrepreneurship from other occupations and changes results compared to the standard Roy (1951) model (more on this below). The crucial economic features driving the result are hence: heterogeneous outside options, a positive relationship between ability and expected productivity, the ability to discard bad projects (for low-ability agents), and the ability to choose inputs (for high-ability agents). The interaction of heterogeneous benefits with heterogeneous outside options generates selection into entrepreneurship from the extremes of the ability distribution. 
Choosing a reservation productivity is equivalent to choosing success and failure probabilities. An additional result can be derived regarding how these vary with ability $a$. Consider only the case of $g^{\prime}>0$, where agents with higher earnings ability also face better productivity distributions. (If $g^{\prime}=0$, the reservation productivity is the same for all $a$.)

Proposition 2 Success probability: If $g^{\prime}(a)>0$, the optimal success probability $1-H\left(\alpha_{R}(a)-\right.$ $g(a))$ increases in $a$, and $\alpha_{R}^{\prime}(a)<g^{\prime}(a)$. As a consequence, in the population, entrepreneurs with high earnings ability reject fewer projects.

Proof. The argument is straightforward for the case of linear $F$. The proof for convex $F$ is more involved and is given in the Appendix. Suppose that $F$ is linear. How does the optimal success probability $1-H$ vary with $a$ ? To start, suppose that it does not vary with $a$ at all. This means that the change in $\alpha_{R}(a)$ exactly compensates the change in $g(a)$ induced by a change in $a$. Now consider equation (3) and note that with linear $F$, the gain from a new draw depends only on how much this draw exceeds the old one, and does not depend on $a$, as $F$ has the same slope everywhere. With the same success probability for all $a$, by the properties of $\Phi^{a}$, the probability distribution of these gains does not change with $a$ either. Hence, the marginal benefit of drawing again does not vary with $a$. The marginal cost $F\left(\alpha_{R}\right)$, however, does, as $\alpha_{R}(a)$ increases with $a$. As a result, a constant success probability cannot be optimal. Instead, $\alpha_{R}$ has to be adjusted such that the marginal benefit keeps step with the marginal cost. This can be achieved by raising $\alpha_{R}$ by less than the increase in $g$, increasing the success probability, thereby increasing the marginal benefit more and the marginal cost less than in the case with constant $1-H . \alpha_{R}^{\prime}<g^{\prime}$ implies that $1-H\left(\alpha_{R}-g\right)$ increases in $a$.

To close the model, the firm productivity distribution can easily be obtained by equating inflows and outflows of firms. Let $\nu(a, \alpha)$ be the measure of firms of productivity $\alpha$ with an owner of ability $a$. This is positive only for $a \leq a_{L}$ or $a \geq a_{H}$ (it is optimal for the owner to start a firm) and for $\alpha \geq \alpha_{R}(a)$ (the firm is productive enough so that the project is pursued). A fraction $\lambda$ of these firms exit every period due to retirement. Entry comes from entrants to the labor market who choose to start a firm, or from entrepreneurs who previously attempted entry, but failed to generate a productive enough project. The inflow into $\nu(a, \alpha)$ hence is

$$
\begin{gathered}
\lambda f(a) \phi^{a}(\alpha)+\lambda f(a) \phi^{a}(\alpha)(1-\lambda) \Phi^{a}\left(\alpha_{R}(a)\right)+\lambda f(a) \phi^{a}(\alpha)(1-\lambda)^{2} \Phi^{a}\left(\alpha_{R}(a)\right)^{2}+\ldots \\
=\frac{\lambda f(a) \phi^{a}(\alpha)}{1-(1-\lambda) \Phi^{a}\left(\alpha_{R}(a)\right)}
\end{gathered}
$$


where $\phi^{a}(\cdot)$ is the $p d f$ associated to $\Phi^{a}(\cdot)$. With an outflow of $\lambda \nu(a, \alpha)$, the stock is given by

$$
\nu(a, \alpha)=\frac{f(a) \phi^{a}(\alpha)}{1-(1-\lambda) \Phi^{a}\left(\alpha_{R}(a)\right)}
$$

for $a \notin\left(a_{L}, a_{H}\right)$ and $\alpha \geq \alpha_{R}(a)$, and zero otherwise.

Note that while the owner ability distribution features two disjoint parts, this does not have to be the case for the firm productivity distribution. This is of course important, as the empirical distribution does not have a disjoint support. If $a_{L}$ and $a_{H}$ are not too far apart, some (relatively) high-productivity firms operated by low-ability people and borderline firms operated by agents just above $a_{H}$ may have similar levels of productivity, in particular if the variance of productivity conditional on ability is high relative to the variance of ability in the population. Variation in the taste for running one's own business and in risk aversion, dimensions abstracted from in the model, would also help to smooth the owner ability distribution and, as a consequence, the firm productivity distribution. Note that while they would also help to explain the existence of small firms (some of them persist because some psychological benefits compensate the owner for lower income), they would not on their own explain the U-shaped relationship between education and entrepreneurship, so heterogeneous ability and selection remain crucial.

Equation (7) also shows the effect that the ability to reject bad draws has on the firm size distribution. Given any $a$, a higher reservation productivity $\alpha_{R}$ raises the probability $\Phi^{a}\left(\alpha_{R}\right)$ of rejecting a given draw. It thereby increases the proportion of firms that ultimately end up with $\alpha>\alpha_{R}$ relative to that fraction without rejection. For any $a \leq a_{L}$ or $a \geq a_{H}$, as starting entrepreneurs reject low productivity draws, they will eventually end up with a good draw. The more stringent the threshold, the stronger this "redistribution" of probability mass to the area above the threshold. While taking time, this benefits aggregate productivity.

Aggregate labor demand follows directly from the firm productivity distribution and the wage. It increases in the number of firms and decreases in the wage. Labor supply is given by total efficiency units of labor of agents with $a \in\left(a_{L}, a_{H}\right)$. As a higher wage makes $W(a)$ steeper and reduces $V(a)$ for all $a$, it shifts $a_{L}$ and $a_{H}$ outwards, increasing labor supply. Labor market clearing thus determines a unique equilibrium wage.

Robustness and extensions. Consider next a few generalizations. The proof of Proposition 1 c) relied on $H$ having full support in $\mathbb{R}$. Relaxing this only affects results in very particular cases. First of all, bounding $\alpha$ from below clearly preserves $\Phi^{0}(0)<1$ and thus the main result. Bounding the support of $H$ from above may eliminate $\Phi^{0}(0)<1$ and thereby entrepreneurship 
by low-ability agents if $g(0)$ is low enough. However, this requires an upper bound on $\alpha$ at 0 or lower for ability-zero agents - a very restrictive assumption. Any higher bound preserves $\Phi^{0}(0)<1$ and entrepreneurship by low-ability agents.

Entry costs however, be they administrative or for financing some sunk investment, may matter. Without them, the cost of entry consists only in foregone wages. So, suppose that productivity is only revealed after some entry cost is paid. Then, when evaluating the costs and benefits of trying again, the benefit of doing so is reduced, as more entry costs would be due. As a result, the reservation productivity $\alpha_{R}$ and the expected value of entry $V(a)$ are both reduced. This shifts the thresholds $a_{L}$ and $a_{H}$ outwards. For high enough entry costs, $a_{L}$ may reach the lower bound of $a$. Entrepreneurship is attractive to low-ability agents if they can search for a good project. Entry costs can make search prohibitively costly for them.

Empirically, this may be plausible, but only up to a point, as low- $a$ individuals can choose low-entry cost industries. Indeed, Lofstrom and Bates (2007) find that college-educated people are more likely to enter high-barrier industries, and people with less education are more likely to enter low-barrier industries. Similarly, Hurst and Lusardi (2004) show that in data from the 1987 National Survey of Small Business Finances (NSSBF) 25\% of new firms were started with less than $\$ 5,000$ in capital, and the median starting capital provided by the founder was $\$ 22,700$. Hence, choice of industry helps overcome entry barriers and preserves the result from the model without entry cost.

Matching the facts. The model presented here matches all the facts on entrepreneurship described in Section 2. In particular, in contrast to all other work on firm heterogeneity, it matches the fact that entrepreneurs are more likely to come from both extremes of the ability distribution (Fact 1). As a consequence, it explains the prominence and persistence of small, low-profit firms (Facts 2 and 3). These firms continue in the market because their owners' outside options in the labor market are even lower. This effect is particularly strong in industries with low entry costs. Another consequence of selection from the extremes is that the variance of returns to entrepreneurship is higher than that of wages (Fact 4).

Moskowitz and Vissing-Jørgensen (2002) discuss some alternative explanations for the fact that a substantial fraction of firms makes little profits, their main candidate being unmeasured returns. Hamilton (2000) also concludes that these are important. While the presence of unmeasured returns seems plausible and could explain Facts 2 and 3, it does not explain Fact 1. Steinberger and Hintermaier (2005) argue that low returns can be interpreted as entrepreneurs' 
investment into information acquisition about their own entrepreneurial ability. While their argument can explain why low returns occur, it cannot explain the persistence of small low-profit firms. Once the information is extracted, only successful firms should continue.

Section 6 presents further evidence on the main predictions of the model. Before that, it is useful to consider the relationship to a close relative, the Roy (1951) model of occupational choice, and to highlight commonalities and differences.

\section{Relationship to the Roy (1951) model of occupational choice}

In the Roy (1951) model of occupational choice, the crucial condition governing that choice relates the correlation between agents' abilities in two sectors to the relative variance of those abilities. ${ }^{6}$ In that model, workers choose between two sectors of activity. Payoffs are known for each individual. In the population, they are bivariate lognormally distributed, with a correlation of $\rho$ between the logarithms of the payoffs. Let the standard deviations of the logarithm of the random payoffs be $\sigma_{\alpha}$ and $\sigma_{a}$, respectively, and assume $\sigma_{\alpha}>\sigma_{a}$. Then, if $\rho \sigma_{\alpha} / \sigma_{a} \geq 1$, outputs are relatively highly correlated, and relatively productive workers tend to choose the sector with the higher variance.

In the model presented in this paper, the situation is different because of search and because one of the occupations is entrepreneurship. The direct counterpart of the Roy model condition would involve $g^{\prime}(a)$, the variance of $a$ in the population, and the conditional variance of $\alpha$. However, in the Roy model, payoffs are linear in abilities. Here in contrast, the fact that one of the occupations is entrepreneurship implies that in that occupation, the payoff is convex in productivity. As a result, as long as $g^{\prime}(a)>0$, there always is a level of ability above which agents choose entrepreneurship.

At the lower end, search makes the difference. To see this more clearly, the model could be brought close to the Roy model by eliminating entrepreneurs' capacity to start again with a new project and restricting them to accept their first draw and to stay in business thereafter, thus eliminating the ability to search (certainly a draconian restriction). By Jensen's inequality, expected firm value $\mathbb{E} F(a)$ then is convex in $\alpha$ and bounded below by $F(\mathbb{E}(\alpha \mid a))$. This implies that $\mathbb{E} F(0)>0$ if $E(\alpha \mid 0)=0$, and low- $a$ agents start firms. However, this is not a very strong result; entrepreneurship by low- $a$ agents disappears if $E(\alpha \mid a)$ is sufficiently low. With search, this does not occur, because what matters is not expected firm value but the probability, or possibility, of a good draw - bad ones can simply be rejected.

\footnotetext{
${ }^{6}$ For an overview of this and related models, see also Sattinger (1993).
} 
With search and entrepreneurship, as long as there is a positive relationship between ability and expected productivity $\left(g^{\prime}>0\right)$, both the size of $g^{\prime}$ and the relative variances of the returns lose importance. The partitioning of the population into occupations changes substantially. These simple extensions thus substantially affect the predictions of the model - allowing more complex predictions, in line with the facts.

\section{Evidence}

The model presented in this paper has two clear, empirically testable predictions. First, Proposition 1 states that individuals with relatively high or low potential wages in dependent employment are more likely to become entrepreneurs (if $g^{\prime}>0$ and $g$ is not too concave). Second, Proposition 2 states that among these, individuals with low potential wages are more likely to abandon a project to look for a better one. This section presents evidence on these predictions using data from the National Longitudinal Survey of Youth (NLSY79).

The representative sample of the NLSY79 contains observations on 6111 individuals over the years 1979 to 2006. They are initially between 14 and 22 years old. Being just at the beginning of their labor market experience, all these individuals face occupational choices, making the NLSY a particularly suitable data set for analyzing the question at hand. To focus on the occupational choice, only individuals who are not in full-time education are considered for the analysis.

Table 4 presents descriptive statistics. Wages are real hourly wages in 1983 dollars, deflated using the Consumer Price Index published by the Bureau of Labor Statistics. Observations below the 0.5 th and above the 99.5 th percentile of the real wage distribution are trimmed. This leaves wage data on 5975 individuals. Information on years of schooling is available for 5367 individuals, and information on the highest degree obtained for 5408 individuals.

Clearly, in the data, individuals who choose to become entrepreneurs may not be entrepreneurs all of the time. There can be various reasons for this; it may take time to generate an entrepreneurial idea or, if there are financial frictions, saving for start-up capital may take time. Still, for brevity, refer to everyone who ever is self-employed or runs a firm as an "entrepreneur". This group comprises almost a third of the sample. Its members spend an average of 5 years, or almost $30 \%$ of the time they spend in the labor market, as entrepreneurs. While their average firm lasts somewhat longer than 3 years, almost half their firms do not make it past the first year. In an average year, $5.7 \%$ of individuals currently are running their own business, $2.4 \%$ attempt to enter with a firm, and $2 \%$ exit. 
Table 4: Descriptive Statistics

\begin{tabular}{lcccc}
\hline \hline & mean & $\begin{array}{c}\text { standard } \\
\text { deviation }\end{array}$ & individuals & observations \\
\hline average wage & 7.56 & 3.82 & 5975 & \\
years of schooling & 13.43 & 2.78 & 5367 & 113844 \\
experience & 7.85 & 5.33 & 5949 & \\
\hline ever entrepreneur & 0.30 & 0.46 & 5949 & \\
$\quad$ duration & 4.96 & 4.65 & 1807 & \\
$\quad$ relative duration & 0.28 & 0.30 & 1807 & \\
$\quad$ share of one-year firms & 0.45 & 0.45 & 1773 & \\
$\quad$ average firm duration & 3.34 & 3.17 & 1784 & 113844 \\
\hline currently entrepreneur & 0.057 & 0.23 & 5949 & 111990 \\
entry & 0.024 & 0.15 & 5949 & 106258 \\
exit & 0.021 & 0.14 & 5949 & \\
one-year firm & 0.012 & 0.11 & 5949 & \\
\hline \hline
\end{tabular}

Notes: Entrepreneurs are all individuals who ever are self-employed or run a firm. Duration is number of observations of entrepreneurship, conditional on being an entrepreneur. Relative duration is relative to total time spent in the labor market. Share of one year firms is share of firms operated by an entrepreneur that last only one year. Entry and exit are the proportion of individuals entering or exiting with a firm in an average year. One-year firms is the proportion of individuals entering with a firm and exiting again within the year. Wages are real hourly wages in 1983 dollars.

Table 5 shows a breakdown of the highest educational degree obtained for the whole sample, for entrepreneurs, and for non-entrepreneurs. In the last column, it also shows entrepreneurship rates for the different education groups. As is evident from the graphical representation of the same data in Figure 3, results from the NLSY are consistent with those from other surveys reported in Section 2.1: entrepreneurship rates are highest among individuals with relatively high or low education.

These results are unweighted group averages, comparing groups of very unequal size. The first column of Table 6 shows that the pattern persists when taking group sizes into account. It reports marginal effects from a probit regression of entrepreneurship on education group dummies. Individuals with intermediate education are significantly less likely to have tried entrepreneurship over the sample period. Column 2 reports results from a tobit regression showing that they also spend significantly less time in entrepreneurship. The pattern is similar for flows: column 3 shows that individuals with relatively high or low education are more likely 
Table 5: Entrepreneurship by educational attainment

\begin{tabular}{lrrrr}
\hline \hline $\begin{array}{l}\text { highest } \\
\text { degree }\end{array}$ & entrepreneurs & $\begin{array}{c}\text { non- } \\
\text { entrepreneurs }\end{array}$ & population & $\begin{array}{c}\text { entrepreneurship } \\
\text { rate }\end{array}$ \\
\hline LHS & $14.4 \%$ & $10.4 \%$ & $11.6 \%$ & $37.3 \%$ \\
HS & $55.3 \%$ & $55.2 \%$ & $55.2 \%$ & $30.6 \%$ \\
LC & $7.4 \%$ & $8.6 \%$ & $8.2 \%$ & $27.3 \%$ \\
C & $17.3 \%$ & $17.9 \%$ & $17.7 \%$ & $30.1 \%$ \\
M & $4.0 \%$ & $6.4 \%$ & $5.7 \%$ & $21.2 \%$ \\
P & $1.1 \%$ & $1.2 \%$ & $1.2 \%$ & $31.3 \%$ \\
$\mathrm{PhD}$ & $0.5 \%$ & $0.3 \%$ & $0.4 \%$ & $42.1 \%$ \\
\hline \hline
\end{tabular}

Notes: Degrees are: less than high school (LHS), high school (HS), less than college (LC), college (C), Master's degree (M), professional degree such as MD, LLD, DDS (P), PhD. The first three columns show the distribution of educational attainment within the occupational groups. The last column shows the proportion of entrepreneurs within each educational group.

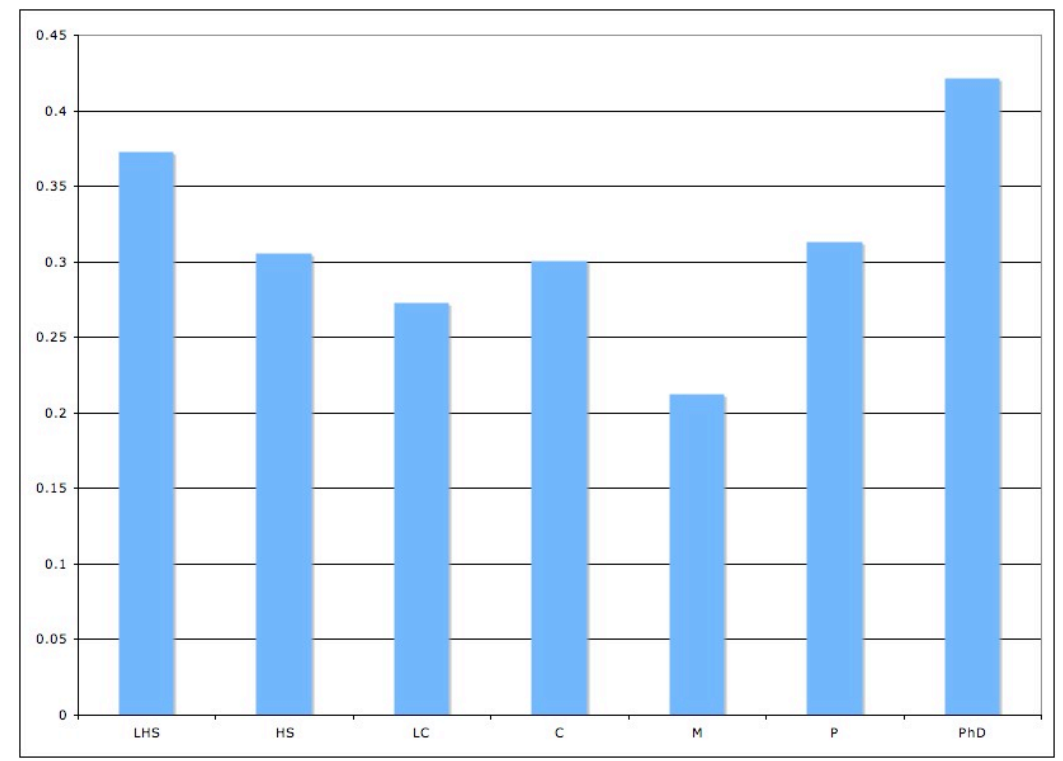

Figure 3: Entrepreneurship rate by educational attainment

Notes: Educational groups are: less than high school (LHS), high school (HS), less than college (LC), college (C), Master's degree (M), professional degree such as MD, LLD, DDS (P), PhD. 
Table 6: Entrepreneurship by educational attainment - regression results

\begin{tabular}{|c|c|c|c|c|c|}
\hline $\begin{array}{l}\text { dependent } \\
\text { variable }\end{array}$ & $\begin{array}{l}\text { individual } \\
\text { ever is } \\
\text { entrepreneur } \\
\text { (1) }\end{array}$ & $\begin{array}{l}\text { time spent as } \\
\text { entrepreneur } \\
(2)\end{array}$ & $\begin{array}{l}\text { individual } \\
\text { becomes } \\
\text { entrepreneur } \\
(3)\end{array}$ & $\begin{array}{l}\text { individual } \\
\text { becomes } \\
\text { entrepreneur } \\
\text { (4) }\end{array}$ & $\begin{array}{l}\text { individual } \\
\text { becomes } \\
\text { entrepreneur } \\
\text { (5) }\end{array}$ \\
\hline $\mathrm{HS}$ & $\begin{array}{l}-0.070^{* * *} \\
(0.020)\end{array}$ & $\begin{array}{l}-0.791^{* *} \\
(0.319)\end{array}$ & $\begin{array}{l}-0.006 \quad * * * \\
(0.002)\end{array}$ & $\begin{array}{l}-0.007^{* * *} \\
(0.002)\end{array}$ & $\begin{array}{l}-0.004^{* *} \\
(0.002)\end{array}$ \\
\hline $\mathrm{LC}$ & $\begin{array}{l}-0.094^{* * *} \\
(0.025)\end{array}$ & $\begin{array}{l}-1.407^{* * *} \\
(0.466)\end{array}$ & $\begin{array}{l}-0.009^{* * *} \\
(0.002)\end{array}$ & $\begin{array}{l}-0.0099^{* * *} \\
(0.002)^{*}\end{array}$ & $\begin{array}{l}-0.006^{* * *} \\
(0.002)\end{array}$ \\
\hline $\mathrm{C}$ & $\begin{array}{l}-0.074^{* * *} \\
(0.022)\end{array}$ & $\begin{array}{l}-1.012^{* * *} \\
(0.378)^{*}\end{array}$ & $\begin{array}{l}-0.003 \\
(0.002)\end{array}$ & $\begin{array}{l}-0.0044^{* * *} \\
(0.002)\end{array}$ & $\begin{array}{l}-0.003 \\
(0.002)\end{array}$ \\
\hline $\mathrm{M}$ & $\begin{array}{l}-0.146^{* * *} \\
(0.025)\end{array}$ & $\begin{array}{l}-2.707^{* * *} \\
(0.554)\end{array}$ & $\begin{array}{l}-0.010)^{* * *} \\
(0.002)\end{array}$ & $\begin{array}{l}-0.010)^{* * *} \\
(0.002)^{*}\end{array}$ & $\begin{array}{l}-0.011^{* * *} \\
(0.002)\end{array}$ \\
\hline $\mathrm{P}$ & $\begin{array}{l}-0.087 \\
(0.052)\end{array}$ & $\begin{array}{l}-1.060 \\
(0.989)\end{array}$ & $\begin{array}{l}-0.005 \\
(0.005)\end{array}$ & $\begin{array}{l}-0.004 \\
(0.005)\end{array}$ & $\begin{array}{c}0.001 \\
(0.007)\end{array}$ \\
\hline $\mathrm{PhD}$ & $\begin{array}{c}0.040 \\
(0.108)\end{array}$ & $\begin{array}{l}-0.112 \\
(1.645)\end{array}$ & $\begin{array}{c}0.004 \\
(0.010)\end{array}$ & $\begin{array}{l}0.005 \\
(0.010)\end{array}$ & $\begin{array}{l}-0.005 \\
(0.009)\end{array}$ \\
\hline experience/100 & & & & $\begin{array}{l}0.273^{* * *} \\
(0.033)\end{array}$ & $\begin{array}{l}0.356^{* * *} \\
(0.055)^{*}\end{array}$ \\
\hline$(\text { experience } / 100)^{2}$ & & & & $\begin{array}{l}-1.2699^{* * *} \\
(0.171)\end{array}$ & $\begin{array}{l}-2.695^{* * *} \\
(0.384)\end{array}$ \\
\hline $\begin{array}{l}\text { previous } \\
\text { entrepreneurship }\end{array}$ & & & & & $\begin{array}{l}0.036^{* * *} \\
(0.003)\end{array}$ \\
\hline constant & & $\begin{array}{l}-2.3099^{* * *} \\
(0.299)^{*}\end{array}$ & & & \\
\hline $\begin{array}{l}\text { observations } \\
\text { groups }\end{array}$ & 5314 & 5314 & $\begin{array}{c}100076 \\
5314\end{array}$ & $\begin{array}{c}100076 \\
5314\end{array}$ & $\begin{array}{l}64961 \\
5314\end{array}$ \\
\hline
\end{tabular}

Notes: Less than high school (LHS) is the omitted group. Degrees are: high school (HS), less than college (LC), college (C), Master's degree (M), professional degree such as MD, LLD, DDS (P), PhD. Regression by probit in columns 1 and 3 to 5 (marginal effects reported), tobit in column 2. Standard errors in parentheses. Errors clustered at the individual level in columns 3 to 5 . Stars indicate statistical significance at the $90 \%\left({ }^{*}\right), 95\left({ }^{* *}\right)$ and $99 \%\left(^{* * *}\right)$ level, respectively. 
to enter entrepreneurship. An exception here are college-educated individuals, for who the entry probability is not statistically significantly different from that of individuals with less than high school. The pattern persists when also controlling for experience, computed as the time spent earning a wage or in self-employment, and for previous self-employment (columns 4 and 5). ${ }^{7}$

While schooling is of course closely related to potential earnings as an employee, the data contain a much better measure of this: wages actually earned. In the model, agents either become workers or attempt entrepreneurship, but never both. However, if for instance it takes time to come up with an entrepreneurial idea, agents may sometimes be workers, and sometimes attempt entrepreneurship. This feature is easy to incorporate into the model; occupational choice follows the same pattern as derived in Section 4, only that agents choosing entrepreneurship have to wait with entry until they come up with an idea, working in the meantime. But while they work, their wages reflect their ability. Then the prediction of the model in terms of earnings ability directly translates into one in terms of wages: agents with relatively high or relatively low wages in employment are more likely to become entrepreneurs, while agents with intermediate wages remain workers.

As wages in employment are observable for almost everyone in the sample (only 3 individuals in the sample become entrepreneurs while never working as employees), it is straightforward to test the relationship between wages and entrepreneurship. Crucially, selection is on observables here. This and the fact that the analysis relies on only few, well-measured variables make results very robust. In particular, it is not necessary to use information on income obtained from entrepreneurship, avoiding all the associated measurement difficulties amply discussed in Hamilton (2000), Moskowitz and Vissing-Jørgensen (2002) and Cagetti and De Nardi (2006).

As an aside, note that results here also suggest that studies of e.g. the return to education in entrepreneurship obtain inconsistent estimates even if they correct for selection into entrepreneurship if they simply let education enter the selection equation linearly. This amounts to misspecifying the selection equation.

Results for several ways of exploring the entrepreneurship-wage relationship are shown in Table 7. The first column shows results from a probit regression of ever being an entrepreneur on a quadratic in wages. The wage is the average real hourly wage earned by the individual when not active as an entrepreneur. The quadratic shape is very significant. Fitted values are

\footnotetext{
${ }^{7}$ In a regression of entry on years of schooling (instead of the degree dummies), schooling is not significant. It becomes significantly negative (at the $90 \%$ level) when also controlling for a quadratic in experience and for previous entrepreneurship. (Results in Table 9 in the Appendix.) This is in line with the difficulty the empirical literature cited in Section 2.1 has with finding a stable relationship between education and entrepreneurship, and underlines the shortcomings of the linear specification of schooling.
} 
Table 7: Entrepreneurship and wages in previous employment - regression results

\begin{tabular}{|c|c|c|c|c|c|}
\hline $\begin{array}{l}\text { dependent } \\
\text { variable }\end{array}$ & $\begin{array}{l}\text { entrepreneur } \\
\text { at least } \\
\text { once } \\
\text { (1) }\end{array}$ & $\begin{array}{l}\text { time spent as } \\
\text { entrepreneur } \\
\text { (2) }\end{array}$ & $\begin{array}{l}\text { enter } \\
\text { entrepreneur- } \\
\text { ship } \\
(3)\end{array}$ & $\begin{array}{l}\text { enter } \\
\text { entrepreneur- } \\
\text { ship } \\
(4)\end{array}$ & $\begin{array}{l}\text { enter } \\
\text { entrepreneur- } \\
\text { ship } \\
(5)\end{array}$ \\
\hline wage/10 & $\begin{array}{l}-0.1799^{* * *} \\
(0.047)^{\text {na }}\end{array}$ & $\begin{array}{l}-2.238^{* * *} \\
(0.709)\end{array}$ & $\begin{array}{l}-0.0099^{* *} \\
(0.004)\end{array}$ & $\begin{array}{l}-0.010^{* * *} \\
(0.004)^{*}\end{array}$ & $\begin{array}{l}-0.005 \\
(0.004)\end{array}$ \\
\hline$(\text { wage } / 10)^{2}$ & $\begin{array}{l}0.055^{* * *} \\
(0.020)\end{array}$ & $\begin{array}{l}0.735^{* *} \\
(0.297)\end{array}$ & $\begin{array}{l}0.0044^{* * *} \\
(0.001)^{2}\end{array}$ & $\begin{array}{l}0.004 \\
(0.001)^{* * *}\end{array}$ & $\begin{array}{l}0.002 \\
(0.001)\end{array}$ \\
\hline experience/100 & & & & $\begin{array}{l}0.2911^{* * *} \\
(0.073)\end{array}$ & $\begin{array}{l}0.162 \\
(0.071)\end{array}$ \\
\hline$(\text { experience/100) })^{2}$ & & & & $\begin{array}{l}-1.926^{* * *} \\
(0.468)\end{array}$ & $\begin{array}{l}-1.438^{* * *} \\
(0.453)\end{array}$ \\
\hline $\begin{array}{l}\text { previous } \\
\text { entrepreneurship }\end{array}$ & & & & & $\begin{array}{l}0.034^{* * *} \\
(0.003)^{*}\end{array}$ \\
\hline constant & & $\begin{array}{l}-2.0011^{* * *} \\
(0.362)\end{array}$ & & & \\
\hline $\begin{array}{l}\text { observations } \\
\text { groups }\end{array}$ & 5949 & 5949 & $\begin{array}{c}55966 \\
5898\end{array}$ & $\begin{array}{c}55966 \\
5898\end{array}$ & $\begin{array}{c}55966 \\
5898\end{array}$ \\
\hline
\end{tabular}

Notes: Wage is average real hourly wage of individual when in dependent employment in the first two columns, and lagged real hourly wage in columns 3 to 5 (all in 1983 dollars). Experience are periods spent either earning a wage or in entrepreneurship. Regression by probit in columns 1 and 3 to 5 (marginal effects reported), tobit in column 2. Standard errors in parentheses. Errors clustered at the individual level in columns 3 to 5 . Stars indicate statistical significance at the $90 \%\left({ }^{*}\right), 95\left({ }^{* *}\right)$ and $99 \%\left({ }^{* * *}\right)$ level, respectively.

plotted in Figure 4; it is clear that the probability of ever being an entrepreneur is highest at the extremes of the wage distribution. Individuals at the extremes of the wage distribution also spend significantly more time in entrepreneurship (column 2), and are significantly more likely to enter entrepreneurship in any given period (column 3). This persists when controlling for experience or for previous entrepreneurship. Previous entrepreneurship is strongly associated with renewed entry. Controlling for it weakens the significance level of the wage. This is of course to be expected, as previous entrepreneurship was already driven by the wage and therefore soaks up its effect. 8

The main prediction of the model is thus borne out very well by the NLSY data: individuals with high or low earnings ability are more likely to become entrepreneurs, and those with

\footnotetext{
${ }^{8}$ Linear probability models yield similar results. Schooling is not significant if included in the regression.
} 


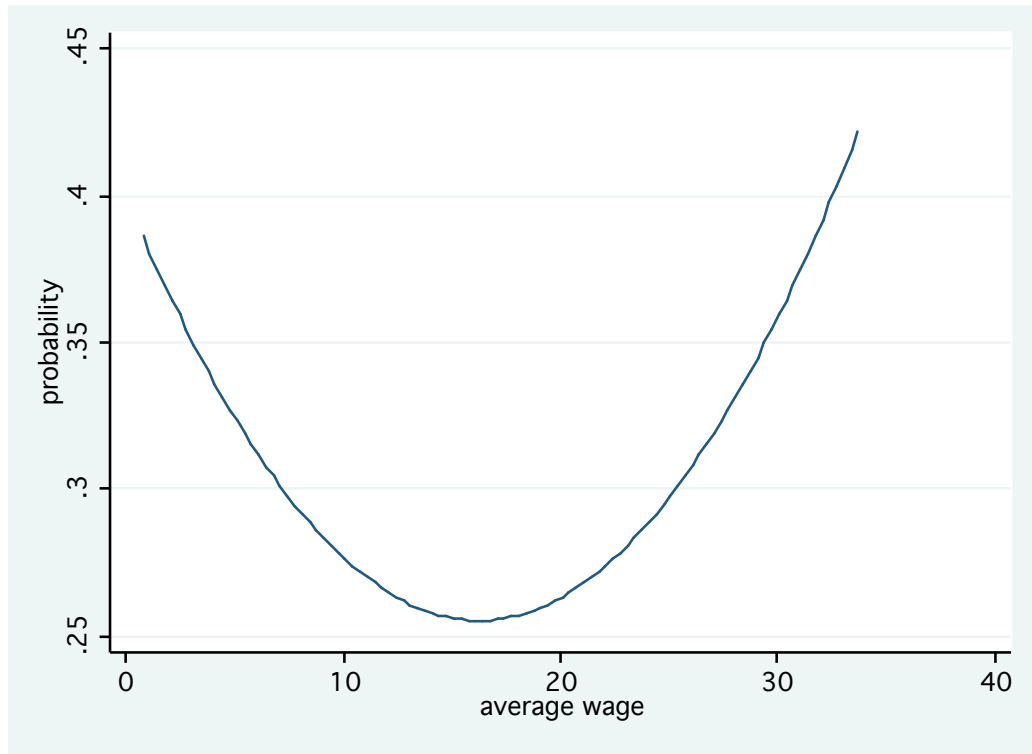

Figure 4: Predicted probability of ever being an entrepreneur as function of the wage

Notes: Fitted from Table 7, column 1. Wage is average real hourly wage of individual when in dependent employment (1983 dollars).

intermediate earnings ability are more likely to become employees. Let us now turn to the second prediction. Proposition 2 says that conditional on entry, entrepreneurs with low earnings ability are more likely to reject projects. This can be tested using the sample of entrepreneurs only. Table 8 shows that the data support the prediction: the average wage is significantly negatively related to the share of an individual's firms that are active only for a single year (column 1). The other two columns show that while firms of individuals with high earnings ability last significantly longer, this is mainly due to the fact that these individuals abandon less firms after the first year, i.e. reject less projects. This pattern is exactly the one that obtains in the model, with low-earnings ability entrepreneurs rejecting more projects initially, but sticking to successful ones. In this, it is complementary to the evidence cited in Section 2.3 that exit rates vary little with firm size once age is controlled for. ${ }^{9}$

\footnotetext{
${ }^{9}$ Table 10 in the Appendix shows that the pattern also holds when using schooling instead of wages. With both schooling and wages quadratic terms are not significant; the relationship appears monotonic, as predicted by the model.
} 
Table 8: Exit behavior and wages - regression results

\begin{tabular}{llcl}
\hline \hline $\begin{array}{l}\text { dependent } \\
\text { variable }\end{array}$ & $\begin{array}{l}\text { share of } \\
\text { one-year firms } \\
(1)\end{array}$ & $\begin{array}{l}\text { average } \\
\text { firm life } \\
(2)\end{array}$ & $\begin{array}{l}\text { average } \\
\text { firm life } \\
(3)\end{array}$ \\
\hline wage & $-0.022^{* * *}$ & $0.093^{* * *}$ & $0.039^{* *}$ \\
& $(0.005)$ & $(0.021)$ & $(0.018)$ \\
share of & & & $-5.746^{* * *}$ \\
one-year firms & & & $(0.18)^{* * *}$ \\
constant & $0.211^{* * *}$ & $2.540^{* * *}$ & 4.900 \\
& $(0.039)$ & $(0.176)$ & $(0.166)$ \\
\hline observations & 2501 & 2501 & 2501 \\
\hline \hline
\end{tabular}

Notes: Sample: individuals who enter entrepreneurship at least once. Wage is average real hourly wage of individual when in dependent employment (1983 dollars). Tobit regressions (censoring at 0 in column 1 and at 1 in columns 2 and 3). Standard errors in parentheses. Stars indicate statistical significance at the $90 \%\left({ }^{*}\right), 95$ $\left.{ }^{* *}\right)$ and $99 \%\left({ }^{* * *}\right)$ level, respectively.

\section{Concluding remarks}

Entrepreneurs make up a substantial proportion of the labor force, and an important one to boot, as they employ others. There is substantial evidence, expanded in this paper, that they are more likely to come from the extremes of the schooling or wage distributions. The main contribution of this paper is to explain this by heterogeneity of labor market prospects (the relevant outside option), combined with search for an adequate project. The ability to reject bad projects puts a lower bound under the value of search. This is particularly valuable to low-ability agents. Because of the low value of their alternative option, it makes them more likely to opt for entrepreneurship. High-ability agents benefit from the ability to leverage high productivity by choosing variable inputs accordingly.

Selection into entrepreneurship from the extremes of the ability distribution naturally explains why the variance of returns to entrepreneurship is so much higher than the variance in wages. In addition, the model provides a plausible rationale for the existence and persistence of small firms. Its prediction that low-ability entrepreneurs are more selective in their search for a good project is borne out well by the data. All these predictions come from a very general model that was on purpose kept as simple as possible, to make clear what drives results.

Enlarging the model, there are several promising avenues for further research. Policy makers often have a rosy view of entrepreneurship. Knowing that there is selection into entrepreneurship from the extremes of the ability distribution puts this into perspective. Some new entrepreneurs, 
but by no means all, are the next Bill Gates (or, in a less glamorous industry, Sam Walton), creating large enterprises. Many new firms are small, and are going to remain small. To explore for instance the aggregate effect of entry subsidies for small enterprises or for entrepreneurship by the unemployed in such a setting, it is crucial to have a model that is able to explain entry at both ends of the distribution. While it would not be surprising to see that entry subsidies successfully encourage entry, it is not evident that they help productivity or welfare if many new entrants stem from the lower end. Another promising application of the model would be to the analysis of informality, in particular in transition economies and developing countries. (Table 3 shows the staggering extent of entrepreneurship "out of necessity" in some of these countries). As modeling the frictions inherent in these applications would substantially cloud the clarity of the exposition, these applications are left for future research. 


\section{References}

Bartelsman, E., Scarpetta, S. and Schivardi, F. (2003), 'Comparative Analysis of Firm Demographics and Survival: Micro-Level Evidence for the OECD Countries', OECD Economics Department Working Paper 348.

Blanchflower, D. G. (2000), 'Self-employment in OECD countries', Labor Economics 7, 471-505.

Borjas, G. J. and Bronars, S. G. (1989), 'Consumer Discrimination and Self-Employment', Journal of Political Economy 97(3), 581-605.

Cagetti, M. and De Nardi, M. (2006), 'Entrepreneurship, Frictions, and Wealth', Journal of Political Economy 114(5), 835-870.

Campbell, J. R. and De Nardi, M. (2007), 'A Conversation with 590 Nascent Entrepreneurs', Federal Reserve Bank of Chicago Working Paper 2007-20.

Chatterjee, S. and Rossi-Hansberg, E. (2008), 'Spin-offs and the Market for Ideas', mimeo .

Evans, D. S. and Leighton, L. S. (1989), 'Some Empirical Aspects of Entrepreneurship', American Economic Review 79(3), 519-535.

Foster, L., Haltiwanger, J. and Krizan, C. J. (2001), Aggregate Productivity Growth: Lessons from Microeconomic Evidence, in C. R. Hulten, E. R. Dean and M. J. Harper, eds, 'New Developments in Productivity Analysis', National Bureau of Economic Research Studies in Income and Wealth, University of Chicago Press, Chicago.

Hamilton, B. H. (2000), 'Does Entrepreneurship Pay? An Empirical Analysis of the Returns to Self-Employment', Journal of Political Economy 108(3), 604-631.

Hipple, S. (2004), 'Self-employment in the United States: an update', Monthly Labor Review 127(7), 13-23.

Hopenhayn, H. (1992), 'Entry, Exit, and Firm Dynamics in Long Run Equilibrium', Econometrica 60(5), 1127-1150.

Hurst, E. and Lusardi, A. (2004), 'Liquidity Constraints, Household Wealth, and Entrepreneurship', Journal of Political Economy 112(2), 319-347.

Jovanovic, B. (1982), 'Selection and the Evolution of Industry', Econometrica 50(3), 649-670.

Jovanovic, B. (1994), 'Firm Formation with Heterogeneous Management and Labor Skills', Small Business Economics 6, 185-191.

Kihlstrom, R. and Laffont, J.-J. (1979), 'A General Equilibrium Entrepreneurial Theory of Firm Formation Based on Risk Aversion', Journal of Political Economy 87(4), 719-748.

Lazear, E. P. (2005), 'Entrepreneurship', Journal of Labor Economics 23(4), 649-680.

Lin, Z., Picot, G. and Compton, J. (2000), 'The Entry and Exit Dynamics of Self-Employment in Canada', Small Business Economics 15(2), 105-125.

Ljungqvist, L. and Sargent, T. J. (2004), Recursive Macroeconomic Theory, MIT Press, Cambridge. 
Lofstrom, M. and Bates, T. (2007), 'African Americans Pursuit of Self-Employment', IZA Discussion Paper $\mathbf{3 1 5 6 .}$

Lucas, R. E. (1978), 'On the size distribution of business firms', Bell Journal of Economics 9, 508-523.

Luttmer, E. (2007), 'Selection, Growth and the Size Distribution of Firms', Quarterly Journal of Economics 122(3), 1103-1144.

McCall, J. J. (1970), 'Economics of Information and Job Search', Quarterly Journal of Economics 84(1), 113-126.

Moskowitz, T. J. and Vissing-Jørgensen, A. (2002), 'The Returns to Entrepreneurial Investment: A Private Equity Premium Puzzle?', American Economic Review 92(4), 745-778.

Roy, A. D. (1951), 'Some Thoughts on the Distribution of Earnings', Oxford Economic Papers 3(2), 135-146.

Sattinger, M. (1993), 'Assignment Models of the Distribution of Earnings', Journal of Economic Literature 31(2), 831-880.

Schjerning, B. and Le Maire, D. (2007), 'Earnings, Uncertainty, and the Self-Employment Choice', Center for Economics and Business Research Discussion Paper 2007-04 04.

Steinberger, T. and Hintermaier, T. (2005), 'Occupational choice and the private equity premium puzzle', Journal of Economic Dynamics and Control 29, 1765-1783.

van der Sluis, J., van Praag, C. and Vijverberg, W. (2003), 'Education and Entrepreneurship in Industrialized Countries', Tinbergen Institute Discussion Paper 2003-046/3. 


\section{Appendix}

\section{A Derivations}

Equation (3): Let the $c d f$ associated to $\phi$ be $\Phi$. Then

$$
\begin{aligned}
F\left(\alpha_{R}(a)\right)=V(a) & =\beta\left[\int_{0}^{\alpha_{R}} F\left(\alpha_{R}(a)\right) \mathrm{d} \Phi\left(\alpha^{\prime} \mid a\right)+\int_{\alpha_{R}}^{\infty} F\left(\alpha^{\prime}\right) \mathrm{d} \Phi\left(\alpha^{\prime} \mid a\right)\right] \\
(1-\beta) F\left(\alpha_{R}(a)\right) \int_{0}^{\alpha_{R}} \mathrm{~d} \Phi\left(\alpha^{\prime} \mid a\right) & =\int_{\alpha_{R}}^{\infty} \beta F\left(\alpha^{\prime}\right)-F\left(\alpha_{R}(a)\right) \mathrm{d} \Phi\left(\alpha^{\prime} \mid a\right) \\
F\left(\alpha_{R}(a)\right) & =\frac{\beta}{1-\beta} \int_{\alpha_{R}}^{\infty} F\left(\alpha^{\prime}\right)-F\left(\alpha_{R}(a)\right) \mathrm{d} \Phi\left(\alpha^{\prime} \mid a\right)
\end{aligned}
$$

Proof of Proposition 2 Proposition 2 states that if $g^{\prime}>0$, entrepreneurs with higher $a$ choose their reservation productivity $\alpha_{R}$ such that the success probability $\chi(a) \equiv 1-H\left(\alpha_{R}-g\right)$ is higher. This is shown in the text for linear $F$. The result then relies on the fact that if $\chi(a)$ is kept constant, the marginal benefit from drawing again is the same for all $a$. With convex $F$, in contrast, the marginal benefit of drawing again increases with $a$ even for constant $\chi$ because higher $a$ moves the productivity distribution the agent faces to a more convex region of $F$, implying higher value gains for a given improvement in the draw of $\alpha$. Still, the same result can be derived.

For this, combine equations (2) and (3) to get the following expression for the reservation productivity:

$$
\frac{\beta}{1-\beta} \int_{\alpha_{R}(a)-g(a)}^{\infty} F\left(\alpha^{\prime}+g(a)\right)-F\left(\alpha_{R}(a)\right) \mathrm{d} H\left(\alpha^{\prime}\right)=F\left(\alpha_{R}(a)\right) .
$$

Then divide both sides by $F\left(\alpha_{R}(a)\right)$ and rearrange to get

$$
\beta \int_{\alpha_{R}(a)-g(a)}^{\infty} \frac{F\left(\alpha^{\prime}+g(a)\right)}{F\left(\alpha_{R}(a)\right)} \mathrm{d} H\left(\alpha^{\prime}\right)=1-\beta H\left(\alpha_{R}(a)-g(a)\right)
$$

or

$$
\beta \int_{\alpha_{R}-g}^{\infty} F\left(\alpha^{\prime}+g\right) \mathrm{d} H\left(\alpha^{\prime}\right)=\left[1-\beta H\left(\alpha_{R}-g\right)\right] F\left(\alpha_{R}\right) .
$$

omitting function arguments wherever this does not risk causing confusion. Again, at the reservation productivity, the expected gain from an additional draw equals the loss from giving up the draw in hand. This relationship holds for all $a$. All functions in involved in equation (8) are continuously differentiable. Then the derivatives of both sides with respect to $a$ also have to be equal:

$$
\begin{aligned}
& \beta \int_{\alpha_{R}-g}^{\infty} F^{\prime}\left(\alpha^{\prime}+g\right) g^{\prime} \mathrm{d} H\left(\alpha^{\prime}\right)-\beta h\left(\alpha_{R}-g\right) F\left(\alpha_{R}\right)\left(\alpha_{R}^{\prime}-g^{\prime}\right) \\
= & {\left[1-\beta H\left(\alpha_{R}-g\right)\right] F^{\prime}\left(\alpha_{R}\right) \alpha_{R}^{\prime}-\beta h\left(\alpha_{R}-g\right)\left(\alpha_{R}^{\prime}-g^{\prime}\right) F\left(\alpha_{R}\right) }
\end{aligned}
$$


or

$$
\beta \int_{\alpha_{R}-g}^{\infty} F^{\prime}\left(\alpha^{\prime}+g\right) g^{\prime} \mathrm{d} H\left(\alpha^{\prime}\right)=\left[1-\beta H\left(\alpha_{R}-g\right)\right] F^{\prime}\left(\alpha_{R}\right) \alpha_{R}^{\prime} .
$$

This equation describes how $\alpha_{R}$ and the success probability $\chi(a)=1-H\left(\alpha_{R}-g\right)$ evolve as $a$ changes. To find how $\alpha_{R}-g$ changes with $a$, rearrange and substitute using equation (8) to obtain

$$
\int_{\alpha_{R}-g}^{\infty} \frac{F^{\prime}\left(\alpha^{\prime}+g\right)}{F^{\prime}\left(\alpha_{R}\right)} \frac{g^{\prime}}{\alpha_{R}^{\prime}} \mathrm{d} H\left(\alpha^{\prime}\right)=\int_{\alpha_{R}-g}^{\infty} \frac{F\left(\alpha^{\prime}+g\right)}{F\left(\alpha_{R}\right)} \mathrm{d} H\left(\alpha^{\prime}\right) .
$$

A Taylor series expansion of the numerators around $\alpha_{R}$ up to the second derivative of $F$ yields an approximation of this as

$$
\begin{aligned}
& \frac{g^{\prime}}{\alpha_{R}^{\prime}} \int_{\alpha_{R}-g}^{\infty} 1+\left(\alpha^{\prime}-\alpha_{R}+g\right) \frac{F^{\prime \prime}\left(\alpha_{R}\right)}{F^{\prime}\left(\alpha_{R}\right)} \mathrm{d} H\left(\alpha^{\prime}\right) \\
& =\int_{\alpha_{R}-g}^{\infty} 1+\left(\alpha^{\prime}-\alpha_{R}+g\right) \frac{F^{\prime}\left(\alpha_{R}\right)}{F\left(\alpha_{R}\right)}+\left(\alpha^{\prime}-\alpha_{R}+g\right)^{2} \frac{F^{\prime \prime}\left(\alpha_{R}\right)}{2 F\left(\alpha_{R}\right)} \mathrm{d} H\left(\alpha^{\prime}\right)
\end{aligned}
$$

or

$$
\begin{aligned}
& {\left[\frac{g^{\prime}}{\alpha_{R}^{\prime}}-1\right] \chi(a)=} \\
& \int_{\alpha_{R}-g}^{\infty}\left(\alpha^{\prime}-\alpha_{R}+g\right)\left[\frac{F^{\prime}\left(\alpha_{R}\right)}{F\left(\alpha_{R}\right)}-\frac{g^{\prime}}{\alpha_{R}^{\prime}} \frac{F^{\prime \prime}\left(\alpha_{R}\right)}{F^{\prime}\left(\alpha_{R}\right)}\right]+\left(\alpha^{\prime}-\alpha_{R}+g\right)^{2} \frac{F^{\prime \prime}\left(\alpha_{R}\right)}{2 F\left(\alpha_{R}\right)} \mathrm{d} H\left(\alpha^{\prime}\right) .
\end{aligned}
$$

With the production function $y=\alpha n^{\gamma}, \gamma \in(0,1)$, this becomes

$$
\left[\frac{g^{\prime}}{\alpha_{R}^{\prime}}-1\right] \chi(a)=\int_{\alpha_{R}-g}^{\infty} \frac{\alpha^{\prime}-\alpha_{R}+g}{(1-\gamma) \alpha_{R}}\left[1-\frac{g^{\prime}}{\alpha_{R}^{\prime}} \gamma\right]+\frac{\left(\alpha^{\prime}-\alpha_{R}+g\right)^{2}}{2 \alpha_{R}^{2}} \frac{\gamma}{(1-\gamma)^{2}} \mathrm{~d} H\left(\alpha^{\prime}\right)
$$

Again, it is immediately clear that $g^{\prime}$ and $\alpha_{R}^{\prime}$ cannot be equal, as otherwise the left hand side would be zero and the right hand side strictly positive. $g^{\prime}<\alpha_{R}^{\prime}$ only worsens this. Hence, it must be that $\alpha_{R}^{\prime}<g^{\prime}{ }^{10}$ Agents with higher earnings ability a choose higher success probabilities to compensate the higher cost of drawing again.

\footnotetext{
${ }^{10}$ With this production function, a longer expansion yields the same result. Inspection of equation (9) shows that the result may not hold in cases where $F^{\prime \prime} / F^{\prime}$ is very large relative to $F^{\prime} / F$ at $\alpha_{R}$, i.e. if the convexity of the value function increases strongly at some $\alpha$. This cannot occur when the production function has constant elasticity with respect to the variable inputs.
} 


\section{B Additional tables}

Table 9: Entrepreneurial entry and schooling - regression results

\begin{tabular}{lccc}
\hline \hline & $(1)$ & $(2)$ & \multicolumn{1}{c}{$(3)$} \\
\hline years of & -0.029 & -0.035 & $-0.041^{*}$ \\
schooling/100 & $(0.023)$ & $(0.023)$ & $(0.02)^{*}$ \\
experience/100 & & $0.301^{* * *}$ & $0.353^{* * *}$ \\
& & $(0.033)$ & $(0.054)$ \\
(experience/100) $^{2}$ & & $-1.416^{* * *}$ & $-2.638^{* * *}$ \\
& & $(0.171)$ & $(0.373)^{* * *}$ \\
previous & & & $0.037^{* * *}$ \\
entrepreneurship & & & $(0.003)$ \\
\hline observations & 99665 & 99665 & 64996 \\
groups & 5275 & 5275 & 5275 \\
\hline \hline
\end{tabular}

Notes: Dependent variable is dummy for entry into self-employment of entrepreneurship. Regression by probit, marginal effects reported. Standard errors in parentheses. Errors clustered at the individual level. (Groups indicates number of individuals.) Stars indicate statistical significance at the $90 \%\left(^{*}\right), 95\left(^{* *}\right)$ and $99 \%\left({ }^{* * *}\right)$ level, respectively.

Table 10: Exit behavior and wages - regression results

\begin{tabular}{|c|c|c|c|}
\hline $\begin{array}{l}\text { dependent } \\
\text { variable }\end{array}$ & $\begin{array}{l}\text { share of } \\
\text { one-year firms } \\
\text { (1) }\end{array}$ & $\begin{array}{l}\text { average } \\
\text { firm life } \\
(2)\end{array}$ & $\begin{array}{l}\text { average } \\
\text { firm life } \\
(3)\end{array}$ \\
\hline schooling & $\begin{array}{l}-0.030^{* * *} \\
(0.007)\end{array}$ & $\begin{array}{l}0.067^{* *} \\
(0.032)\end{array}$ & $\begin{array}{l}-0.003 \\
(0.028)\end{array}$ \\
\hline $\begin{array}{l}\text { share of } \\
\text { one-year firms }\end{array}$ & & & $\begin{array}{l}-5.686^{* * *} \\
(0.192)\end{array}$ \\
\hline constant & $\begin{array}{l}0.457^{* * *} \\
(0.090)\end{array}$ & $\begin{array}{l}2.297^{* * *} \\
(0.429)\end{array}$ & $\begin{array}{l}5.201 \\
(0.383)\end{array}$ \\
\hline observati & 2212 & 2212 & 2212 \\
\hline
\end{tabular}

Notes: Sample: individuals who enter entrepreneurship at least once. Schooling in years. Tobit regressions (censoring at 0 in column 1 , at 1 in columns 2 and 3). Standard errors in parentheses. Stars indicate statistical significance at the $90 \%\left({ }^{*}\right), 95\left(^{* *}\right)$ and $99 \%\left({ }^{* * *}\right)$ level, respectively. 